\title{
Predictors of diffuse alveolar damage in patients with acute respiratory distress syndrome: a retrospective analysis of clinical autopsies
}

Arnaud W. Thille ${ }^{1,2^{*}}$, Oscar Peñuelas ${ }^{3,4}$, José A. Lorente ${ }^{3,4}$, Pilar Fernández-Segoviano ${ }^{5}$, José-Maria Rodriguez ${ }^{5}$, José-Antonio Aramburu ${ }^{5}$, Julian Panizo ${ }^{6}$, Andres Esteban ${ }^{3,4}$ and Fernando Frutos-Vivar ${ }^{3,4}$

\begin{abstract}
Background: Although diffuse alveolar damage (DAD) is considered the typical histological pattern of acute respiratory distress syndrome (ARDS), only half of patients exhibit this morphological hallmark. Patients with DAD may have higher mortality than those without DAD. Therefore, we aimed to identify the factors associated with DAD in patients with ARDS.

Methods: We analyzed autopsy samples of 356 patients who had ARDS at the time of death. DAD was assessed by two pathologists, and ARDS criteria were evaluated by two intensivists. Criteria for severe ARDS included the degree of hypoxemia and the ancillary variables of the current Berlin definition assessed within $48 \mathrm{~h}$ before death: radiographic severity, high positive end-expiratory pressure (PEEP) level, and physiological variables (i.e., altered respiratory system compliance and large anatomic dead space).

Results: After multivariable analysis, high PEEP levels, physiological variables, and opacities involving only three quadrants on chest radiographs were not associated with DAD. The four markers independently associated with DAD were (1) duration of evolution (OR 3.29 [1.95-5.55] for patients with ARDS $\geq 3$ days, $p<0.001$ ), (2) degree of hypoxemia (OR 3.92 [1.48-10.3] for moderate ARDS and 6.18 [2.34-16.3] for severe ARDS, $p<0.01$ for both), (3) increased dynamic driving pressure (OR 1.06 [1.04-1.09], $p=0.007$ ), and (4) radiographic severity (OR 2.91 [1.47-5.75] for patients with diffuse opacities involving the four quadrants, $p=0.002$ ). DAD was found in two-thirds of patients with a ratio of partial pressure of arterial oxygen to fraction of inspired oxygen $\leq 100 \mathrm{mmHg}$ and opacities involving the four quadrants.
\end{abstract}

Conclusions: In addition to severe hypoxemia, diffuse opacities involving the four quadrants were a strong marker of DAD.

Keywords: Acute respiratory distress syndrome, Diffuse alveolar damage, Mechanical ventilation, Intensive care unit

\footnotetext{
* Correspondence: aw.thille@gmail.com

${ }^{1} \mathrm{CHU}$ de Poitiers, Réanimation Médicale, Poitiers, France

${ }^{2}$ INSERM CIC 1402 ALIVE Group, Université de Poitiers, 2 rue la Milétrie, 86021

Poitiers Cedex, France

Full list of author information is available at the end of the article
} 


\section{Background}

Acute respiratory distress syndrome (ARDS) was described for the first time in 1967 by Ashbaugh and colleagues [1]. They reported 12 patients without a history of underlying cardiac or pulmonary disease who rapidly developed acute hypoxemia, stiff lungs, and diffuse opacities visualized by chest radiography. An autopsy was performed in the seven deceased patients, and a striking finding was the presence of hyaline membranes in all but one patient [1]. Diffuse alveolar damage (DAD), including the presence of hyaline membranes, interstitial edema, cell necrosis and proliferation, or fibrosis, is considered the typical histological pattern of ARDS [2, 3]. However, this histological hallmark of DAD is not observed in all patients fulfilling the criteria for ARDS. In the literature, the proportion of DAD among patients with ARDS ranged from $45 \%$ to $66 \%$ in autopsy studies [4-7] and from $14 \%$ to $60 \%$ in open lung biopsy studies [8-14]. Patients without DAD exhibited other histological patterns, such as diffuse interstitial pneumonia, pulmonary infarction or hemorrhage, lymphangitis, cancer infiltration, bacterial pneumonia without DAD, or no lung histological abnormalities at all.

In a recent meta-analysis including all patients with ARDS who had open lung biopsy, only $51 \%$ of them had DAD at histological examination [15]. This metaanalysis showed that patients with ARDS and DAD had higher mortality than those without DAD. In a previous study analyzing autopsy findings from patients with ARDS according to the Berlin definition, DAD proportion was correlated to degree of hypoxemia and was $12 \%$ in mild ARDS, $40 \%$ in moderate ARDS, and 58\% in severe ARDS [7]. Whether other markers could be associated with the presence of DAD in patients with ARDS has been poorly assessed. Their identification could contribute to better management of ARDS. We consequently aimed to identify markers associated with DAD from clinical autopsies in patients fulfilling the criteria for ARDS at the time of death.

\section{Methods}

This is a secondary analysis of a large database of clinical autopsies [7].

\section{Inclusion of patients}

We analyzed the 356 patients with ARDS who died and had a clinical autopsy between 1 January 1991 and 31 December 2010 in the 18-bed intensive care unit (ICU) at the University Hospital of Getafe in Spain. We systematically requested informed consent from patients' relatives for both clinical autopsy and potential use of tissue samples for subsequent data analysis in research or teaching purposes, and the study was approved by the institutional review board.
All medical files of patients having had an autopsy were reviewed by two intensivists blinded to the autopsy findings to determine if patients fulfilled the clinical criteria for ARDS at the time of death. The diagnosis of ARDS was established by consensus of the two intensivists and resolved by a third intensivist in case of discrepancies. According to the Berlin definition [16], patients were considered to have the diagnosis of ARDS if they had (1) acute respiratory failure not fully explained by cardiac failure or fluid overload; (2) bilateral opacities not fully explained by effusions, lobar/lung collapse, or nodules on the chest radiograph or the CT scan; and/or (3) onset within 1 week after a known clinical insult or new/worsening respiratory symptoms.

\section{Data collection and definition of severity}

We collected demographic variables (age, sex, severity score at ICU admission), reasons for ICU admission and mechanical ventilation, duration of mechanical ventilation, and date of the onset of risk factor for ARDS. Patients were considered to have a pulmonary risk factor for ARDS if they had a diagnosis of pneumonia, aspiration, inhalation, or lung contusion, as well as an extrapulmonary risk factor for ARDS if they had a diagnosis of sepsis, shock, multiple trauma or transfusion, or pancreatitis. Severity was defined according to degree of hypoxemia, and ARDS was considered severe if the ratio of partial pressure of arterial oxygen to fraction of inspired oxygen $\left(\mathrm{PaO}_{2} / \mathrm{FiO}_{2}\right)$ was $\leq 100 \mathrm{mmHg}$, moderate if $\mathrm{PaO}_{2} / \mathrm{FiO}_{2}$ was between 101 and $200 \mathrm{mmHg}$, and mild if $\mathrm{PaO}_{2} / \mathrm{FiO}_{2}$ was between 201 and $300 \mathrm{mmHg}$, in all cases using a PEEP level $\geq 5 \mathrm{cmH}_{2} \mathrm{O}$.

We also distinguished the more severe patients according to the four ancillary variables proposed by the Berlin definition for severe ARDS: (1) radiographic severity with more extensive opacities involving three or four quadrants compared with patients fulfilling the minimal criterion of "bilateral opacities" (two quadrants), altered respiratory system compliance $\left(\mathrm{C}_{\mathrm{RS}} \leq 40 \mathrm{ml} / \mathrm{cmH}_{2} \mathrm{O}\right)$, large anatomical dead space as indicated by high corrected expired volume per minute ( $\geq 10 \mathrm{~L} /$ minute), and positive endexpiratory pressure $(\mathrm{PEEP}) \geq 10 \mathrm{cmH}_{2} \mathrm{O}$. Because plateau pressure was not measured over the whole period of the study, we calculated dynamic driving pressure (expressed as centimeters of water) as the difference between peak inspiratory pressure minus PEEP, and dynamic compliance of the respiratory system, and not static $C_{R S}$, as tidal volume divided by peak inspiratory pressure minus PEEP and expressed in milliliters per centimeter of water. Corrected expired volume per minute was calculated as the measured minute ventilation multiplied by the partial pressure of arterial carbon dioxide $\left(\mathrm{PaCO}_{2}\right)$ divided by $40 \mathrm{mmHg}$. 
In all patients with ARDS, we collected ventilatory settings, arterial blood gas results, and chest radiography findings within $48 \mathrm{~h}$ before death. Radiographic severity was assessed by two intensivists, and extent of opacities was classified according to the number of quadrants involved (two, three, or all four). In case of disagreement, discrepancies were resolved by a consensus of three physicians, including a third intensivist or a radiologist blinded to the autopsy findings. Patients with four quadrants involved were those with bilateral and diffuse infiltrates without pleural effusion or lung collapse.

\section{Pathologic criteria for DAD}

All our autopsy examinations were performed within $12 \mathrm{~h}$ of death using the same methodology for over 20 years, as already detailed in our previous studies in this field of investigation [4, 7, 17-19]. After removal from the thorax, the lungs were inflated at a pressure of $35 \mathrm{cmH}_{2} \mathrm{O}$ and were fixed in blocks with $10 \%$ formalin. We took samples for microscopic analysis from each pulmonary lobe and additional samples from areas with macroscopic injuries. All samples were stored from the time of autopsy and were subsequently independently analyzed by two pathologists who had no clinical information. A third pathologist, also blinded, resolved any discrepancies. Criteria for DAD were hyaline membranes plus at least one of the following: intraalveolar edema, cell necrosis of type I alveolar cells, proliferation of type II alveolar cells (cuboidal cells), interstitial proliferation of fibroblasts and myofibroblasts, or organizing interstitial fibrosis [2, 3, 17].

\section{Statistical analysis}

Patients with ARDS and DAD and those with ARDS without DAD were compared using the chi-square test or Fisher's exact test for categorical variables and Student's $t$ test or the Mann-Whitney $U$ test for continuous variables when appropriate. Continuous variables were expressed as mean \pm SD or as median and IQR (25th-75th percentiles). Qualitative variables were expressed as frequency and percent.

To identify independent factors associated with DAD, we performed a multivariate logistic regression analysis using a backward selection procedure including in the maximal model all nonredundant variables associated with DAD with a $p$ value $<0.15$.

A two-tailed $p$ value $<0.05$ was considered statistically significant. All analyses were performed using SAS version 9.2 software (SAS Institute, Cary, NC, USA).

\section{Results}

Among the 356 patients analyzed who fulfilled the criteria for ARDS at the time of death, only $45 \%$ of them (159 patients) had DAD at autopsy examination, whereas
8\% (27 patients) had normal lungs. Using univariate analysis (Table 1), patients with DAD were more likely than those without DAD to have pneumonia as the lung insult triggering ARDS and also to be female, although they received lower tidal volumes than males $(580 \pm 135$ vs. $644 \pm 143 \mathrm{ml}, p<0.001)$. Patients with DAD were more hypoxemic and more hypercapnic. They also had more increased dynamic driving pressure, and all ancillary variables proposed for severe ARDS in the Berlin definition were associated with DAD (Table 1). Patients with DAD had more altered compliance of the respiratory system, larger anatomical dead space as indicated by higher expired volume per minute corrected by $\mathrm{PaCO}_{2}$, higher PEEP levels, and more diffuse opacities on chest radiographs. Discrepancies of chest radiographic analysis concerning the number of quadrants involved were found in $19 \%$ of the cases $(n=69)$ and were resolved by a consensus of three physicians. At autopsy examination, the lungs from patients with DAD were heavier than those without DAD.

After adjustment, no ancillary variables remained significantly associated with DAD (Table 2). Using multivariate logistic regression analysis, the four markers independently associated with DAD were (1) duration of evolution of ARDS of more than 3 days, (2) severe hypoxemia, (3) increased dynamic driving pressure, and (4) diffuse opacities involving the four quadrants on chest radiographs (Table 2). The extent of opacities involving only three quadrants did not remain significantly associated with DAD.

DAD was significantly more frequent in patients with extensive infiltrates involving the four quadrants than in those involving two or three quadrants: 101 (59\%) of 171 patients vs. $58(31 \%)$ of 185 patients $(p<0.001)$ (Fig. 1$)$. Among the patients with severe ARDS $\left(\mathrm{PaO}_{2} / \mathrm{FiO}_{2} \leq 100 \mathrm{mmHg}\right), \mathrm{DAD}$ was found in $66 \%$ of patients with extensive opacities involving the four quadrants vs. $44 \%$ and $48 \%$ in those with opacities involving two or three quadrants, respectively $(p=0.02)$ (Fig. 2). Compared with patients without DAD, those with DAD were more likely to die as a result of refractory hypoxemia: $44(28 \%)$ of the 159 patients vs. 27 (14\%) of 197 patients $(p=0.03)$.

Patients with moderate or severe ARDS who died during the most recent period (between 2000 and 2010) received lower tidal volumes and were less likely to have DAD at autopsy examination than those from the earliest period (between 1991 and 1999) (Fig. 3).

\section{Discussion}

\section{Key findings}

In this large study of clinical autopsies performed in patients who fulfilled all the criteria for ARDS at the time of death, a typical histological pattern of DAD was observed in less than half of the patients and was significantly more 
Table 1 Comparison of patients with acute respiratory distress syndrome with or without diffuse alveolar damage patterns at histological examination

\begin{tabular}{|c|c|c|c|}
\hline & ARDS without DAD $(n=197)$ & ARDS with DAD $(n=159)$ & $p$ Value \\
\hline \multicolumn{4}{|l|}{ Characteristics of the patients } \\
\hline Age, years & $66.4 \pm 14.0$ & $64.3 \pm 14.7$ & 0.17 \\
\hline Female sex, $n(\%)$ & $58(29.4 \%)$ & $68(42.8 \%)$ & 0.01 \\
\hline SAPS II, points & $55.5 \pm 19.6$ & $50.9 \pm 16.1$ & 0.02 \\
\hline Duration of MV before death, days & $12.7 \pm 21.7$ & $13.1 \pm 11.0$ & 0.82 \\
\hline Duration of ARDS evolution $\geq 72$ h, $n$ (\%) & $101(51 \%)$ & $128(81 \%)$ & $<0.01$ \\
\hline \multicolumn{4}{|l|}{ Risk factor triggering ARDS } \\
\hline Pneumonia, $n(\%)$ & $62(31.5 \%)$ & $66(41.5 \%)$ & 0.04 \\
\hline Other pulmonary risk factors of ARDS, $n(\%)$ & $12(6.1 \%)$ & $7(4.4 \%)$ & 0.48 \\
\hline Shock, $n(\%)$ & $118(59.9 \%)$ & $83(52.2 \%)$ & 0.14 \\
\hline Extrapulmonary sepsis, $n(\%)$ & $73(37.1 \%)$ & $56(35.2 \%)$ & 0.72 \\
\hline Pancreatitis, $n(\%)$ & $12(6.1 \%)$ & $7(4.4 \%)$ & 0.48 \\
\hline \multicolumn{4}{|l|}{ Blood gases } \\
\hline $\mathrm{PaO}_{2}, \mathrm{mmHg}$ & $93 \pm 37$ & $79 \pm 27$ & $<0.01$ \\
\hline $\mathrm{PaO}_{2} / \mathrm{FiO}_{2}, \mathrm{mmHg}$ & $140 \pm 67$ & $104 \pm 53$ & $<0.01$ \\
\hline $\mathrm{PaCO}_{2}, \mathrm{mmHg}$ & $44.5 \pm 12.8$ & $49.1 \pm 15.0$ & $<0.01$ \\
\hline Severity of hypoxemia & & & $<0.01$ \\
\hline $200<\mathrm{PaO}_{2} / \mathrm{FiO}_{2} \leq 300 \mathrm{mmHg}, n(\%)$ & $43(22 \%)$ & $6(4 \%)$ & \\
\hline $100<\mathrm{PaO}_{2} / \mathrm{FiO}_{2} \leq 200 \mathrm{mmHg}, n(\%)$ & $85(43 \%)$ & $56(35 \%)$ & \\
\hline $\mathrm{PaO}_{2} / \mathrm{FiO}_{2} \leq 100 \mathrm{mmHg}, n(\%)$ & $69(35 \%)$ & $97(61 \%)$ & \\
\hline \multicolumn{4}{|l|}{ Ventilatory settings } \\
\hline Tidal volume, ml & $620 \pm 133$ & $623 \pm 157$ & 0.87 \\
\hline Respiratory rate, cycles/minute & $20 \pm 6$ & $22 \pm 7$ & $<0.01$ \\
\hline Minute ventilation, L/minute & $11.9 \pm 3.2$ & $13.1 \pm 3.4$ & $<0.01$ \\
\hline $\mathrm{FiO}_{2}$ & $0.75 \pm 0.25$ & $0.85 \pm 0.22$ & $<0.01$ \\
\hline PEEP, $\mathrm{cmH}_{2} \mathrm{O}$ & $7.9 \pm 4.5$ & $9.6 \pm 4.1$ & $<0.01$ \\
\hline PEEP $\geq 10 \mathrm{cmH}_{2} \mathrm{O}, n(\%)$ & $91(46 \%)$ & $106(67 \%)$ & $<0.01$ \\
\hline \multicolumn{4}{|l|}{ Physiological parameters } \\
\hline Peak pressure, $\mathrm{CmH}_{2} \mathrm{O}$ & $37 \pm 10$ & $44 \pm 10$ & $<0.01$ \\
\hline Dynamic driving pressure (peak - PEEP), $\mathrm{CmH}_{2} \mathrm{O}$ & $28 \pm 11$ & $34 \pm 9$ & $<0.01$ \\
\hline Dynamic compliance, $\mathrm{ml} / \mathrm{cmH}_{2} \mathrm{O}$ & $24 \pm 11$ & $20 \pm 7$ & $<0.01$ \\
\hline Dynamic compliance < $40 \mathrm{ml} / \mathrm{cmH}_{2} \mathrm{O}, n(\%)$ & $174(88 \%)$ & $155(97 \%)$ & $<0.01$ \\
\hline VE corrected $\mathrm{PaCO}_{2}, \mathrm{~L} /$ minute & $13 \pm 5$ & $16 \pm 7$ & $<0.01$ \\
\hline VE corrected $\mathrm{PaCO}_{2} \geq 10 \mathrm{~L} /$ minute, $n(\%)$ & $135(69 \%)$ & $133(84 \%)$ & $<0.01$ \\
\hline Extent of infiltrates on chest radiograph & & & $<0.01$ \\
\hline Two quadrants, $n$ (\%) & $64(32 \%)$ & $17(11 \%)$ & \\
\hline Three quadrants, $n(\%)$ & $63(32 \%)$ & $41(26 \%)$ & \\
\hline Four quadrants, $n(\%)$ & $70(36 \%)$ & $101(63 \%)$ & \\
\hline Lung weight at autopsy examination, g & $1567 \pm 709$ & $1848 \pm 748$ & $<0.01$ \\
\hline
\end{tabular}

Abbreviations: ARDS Acute respiratory distress syndrome, DAD Diffuse alveolar damage, MV Mechanical ventilation, SAPS Simplified Acute Physiology Score II, PEEP Positive end-expiratory pressure, $\mathrm{VE}$ Minute ventilation, $\mathrm{PaCO}_{2}$ Partial pressure of arterial carbon dioxide, $\mathrm{PaO}_{2}$, Partial pressure of arterial oxygen, $\mathrm{PaO}_{2} / \mathrm{FiO}_{2}$ Ratio of partial pressure of arterial oxygen to fraction of inspired oxygen 
Table 2 Predictors of diffuse alveolar damage in patients with clinical criteria for acute respiratory distress syndrome

\begin{tabular}{|c|c|c|}
\hline & Bivariate test, OR $(95 \% \mathrm{Cl}), p$ value & Multivariate logistic regression, OR $(95 \% \mathrm{Cl}), p$ value \\
\hline \multicolumn{3}{|l|}{ Characteristics of the patients } \\
\hline Female sex, $n(\%)$ & $1.79(1.15-2.78), p<0.01$ & Not significant \\
\hline Pneumonia, $n(\%)$ & $1.54(0.99-2.39), p=0.05$ & Not significant \\
\hline \multicolumn{3}{|l|}{ Duration of evolution of ARDS } \\
\hline$>72 \mathrm{~h}$ & $3.92(2.43-6.37), p<0.001$ & $3.29(1.95-5.55), p<0.001$ \\
\hline Severity of hypoxemia & $<0.0001$ & \\
\hline Mild ARDS $(n=49)$ & Reference & \\
\hline Moderate ARDS $(n=141)$ & $4.72(1.88-11.8), p<0.001$ & $3.92(1.48-10.3), p=0.006$ \\
\hline Severe ARDS $(n=166)$ & $10.1(4.06-24.9), p<0.001$ & $6.18(2.34-16.3), p<0.001$ \\
\hline \multicolumn{3}{|l|}{ Ancillary variables of severity } \\
\hline PEEP $\geq 10 \mathrm{cmH}_{2} \mathrm{O}$ & $2.33(1.51-3.59), p<0.001$ & Not significant \\
\hline Dynamic compliance $<40 \mathrm{ml} / \mathrm{cmH}_{2} \mathrm{O}$ & $5.12(1.73-15.1), p<0.01$ & Not significant \\
\hline VE corrected $\mathrm{PaCO}_{2} \geq 10 \mathrm{~L} /$ minute & $2.34(1.40-3.93), p<0.01$ & Not significant \\
\hline $\mathrm{PaCO}_{2}>45 \mathrm{mmHg}$ & $1.73(1.14-2.65), p=0.01$ & Not significant \\
\hline Dynamic driving pressure (peak - PEEP), $\mathrm{cmH}_{2} \mathrm{O}$ & $1.06(1.04-1.09), p<0.001$ & $1.06(1.04-1.09), p=0.007$ \\
\hline Extent of infiltrates on chest radiograph & $<0.0001$ & \\
\hline Two quadrants & Reference & \\
\hline Three quadrants & $2.45(1.26-4.76), p<0.01$ & $1.63(0.79-3.39), p=0.19$ \\
\hline Four quadrants & $5.43(2.93-10.1), p<0.0001$ & $2.91(1.47-5.75), p=0.002$ \\
\hline
\end{tabular}

Abbreviations: ARDS Acute respiratory distress syndrome, DAD Diffuse alveolar damage, PEEP Positive end-expiratory pressure, VE Minute ventilation; PaCO ${ }_{2}$ Partial pressure of arterial carbon dioxide

All variables nonredundant associated with DAD with a $p$ value $<0.15$ were included in the maximal model, including severity score, sex, pneumonia as a risk factor for ARDS, duration of ARDS evolution $>72 \mathrm{~h}$, severity of hypoxemia (mild, moderate, or severe using mild as the reference), $\mathrm{PEEP} \geq 10 \mathrm{cmH}_{2} \mathrm{O}$, dynamic compliance of the respiratory system $<40 \mathrm{ml} / \mathrm{cmH}_{2} \mathrm{O}$, expired minute volume corrected by $\mathrm{PaCO}_{2} \geq 10 \mathrm{~L} /$ minute, hypercapnia defined as $\mathrm{PaCO}_{2}>45 \mathrm{mmHg}$, dynamic driving pressure defined as peak pressure minus PEEP, and the extent of radiological infiltrates (two, three, or four quadrants using two quadrants as the reference)

Bold data are variables that remained significanltly associated with DAD after multivariate logistic regression

Proportion of DAD (in \%)
according to radiologic severity on chest radiograph
(number of quadrants involved)
Fig. $\mathbf{1}$ Bar graph showing the proportion of patients with diffuse alveolar damage (DAD) according to radiologic severity (extent of opacities on
chest radiographs) in mild, moderate, and severe acute respiratory distress syndrome (ARDS). All in all, DAD was significantly more frequent in
patients with extensive infiltrates involving the four quadrants than in the others: 101 (59\%) of 171 patients with four quadrants vs. 58 (31\%) of
185 patients with two or three quadrants ( $p<0.001)$




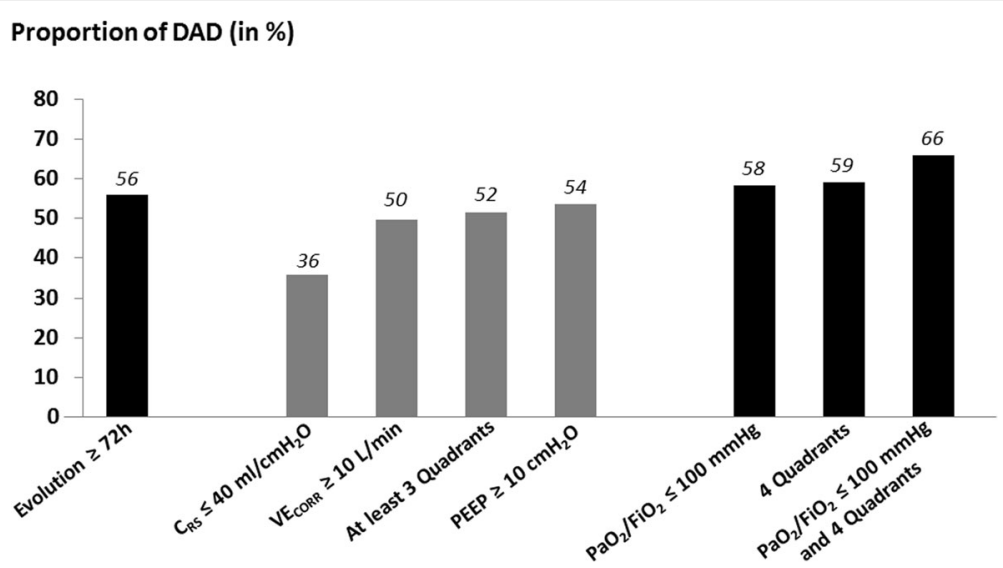

Fig. 2 Bar graph showing the proportion of patients with diffuse alveolar damage (DAD) according to characteristics of the patients and criteria for severity of acute respiratory distress syndrome (ARDS). After multivariate analysis, the four variables independently associated with DAD (indicated by black bars) were duration of evolution of ARDS ( $\geq 3$ days), severity of hypoxemia, increased dynamic driving pressure, and radiologic severity with diffuse opacities involving the four quadrants. $C_{R S}$ Respiratory system compliance, $\mathrm{PaO}_{2} / \mathrm{FiO}_{2}$ Ratio of partial pressure of arterial oxygen to fraction of inspired oxygen, PEEP Positive end-expiratory pressure, $V E_{C O R R}$ Corrected expired volume per minute

frequent in patients with ARDS for $>3$ days, in most patients with hypoxemia, in those with more increased dynamic driving pressure, and in patients with extensive opacities involving the four quadrants. Therefore, the degree of hypoxemia, the driving pressure, and the radiographic severity could be strong non-patient-dependent markers of DAD and could be easily assessed at the bedside.

\section{Markers of DAD}

In addition to the degree of hypoxemia, the current Berlin definition proposes the following four ancillary variables to identify severe ARDS [16]: altered respiratory system compliance $\leq 40 \mathrm{ml} / \mathrm{cmH}_{2} \mathrm{O}$, high minute ventilation corrected by $\mathrm{PaCO}_{2} \geq 10 \mathrm{~L} /$ minute (indicating a large anatomical dead space), high PEEP levels $\geq 10 \mathrm{cmH}_{2} \mathrm{O}$, and radiologic severity with extensive opacities involving at least three quadrants. In a previous study, patients with DAD had a lower $\mathrm{PaO}_{2} / \mathrm{FiO}_{2}$ ratio and lower respiratory system compliance [20]. However, the extent of opacities on chest radiographs was not assessed therein. After multivariate analysis including radiographic severity, altered respiratory system compliance $\left(<40 \mathrm{ml} / \mathrm{cmH}_{2} \mathrm{O}\right)$ did not remain significantly associated with DAD, whereas increased dynamic driving pressure and extensive opacities involving the four quadrants (and not three quadrants) constituted two factors independently associated with DAD in addition to hypoxemia severity.

We previously reported that DAD was markedly more frequent in most patients with hypoxemia, particularly after $\geq 3$ days of evolution of ARDS [7]. However, in this previous study, we did not assess factors independently
Tidal volume (in $\mathrm{ml}$ )

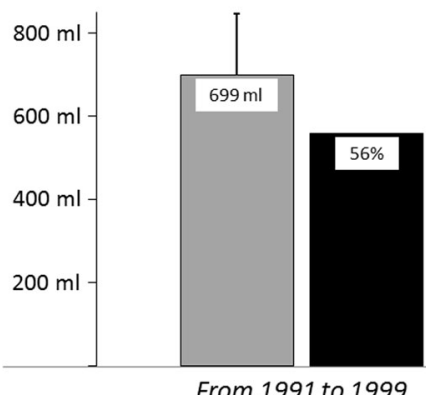

Proportion of DAD (\%)

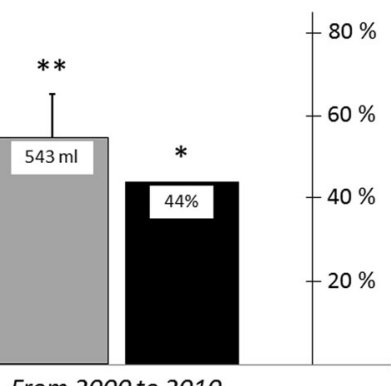

From 2000 to 2010

Fig. 3 Bar graph showing temporal changes of tidal volume (gray bars) in patients with moderate or severe acute respiratory distress syndrome and the proportion of patients with diffuse alveolar damage (DAD) at autopsy examination (black bars) between the first decade at left (1991-1999) and the second decade at right (2000-2010) (i.e., before and after the era of reduction in tidal volumes). From 2000, tidal volumes were significantly reduced (from $699 \pm 148 \mathrm{ml}$ to $543 \pm 106 \mathrm{ml}, p<0.0001$ ), and this reduction was associated with a parallel reduction in the proportion of patients with DAD (from $56 \%$ to $44 \%, p=0.03$ ), suggesting that low tidal volumes may attenuate DAD. ${ }^{*} p<0.05,{ }^{* *} p<0.01$ 
associated with DAD as we did in the present study. In addition to degree of hypoxemia and duration of evolution, we have now identified two other predictors of DAD: altered dynamic driving pressure and radiographic severity with diffuse opacities. Our data confirm that, even after adjustment for other variables, duration of evolution was independently associated with DAD. The absence of hyaline membranes during the first 3 days may be due to short duration of the process because hyaline membrane formation may take 2-3 days [2]. Moreover, patients with DAD had heavier lungs than the others, meaning that they had more alveolar and interstitial edema, one of the criteria for DAD. Although tidal volumes did not differ between patients with DAD and those without DAD, we found that the reduction of tidal volumes in the age of protective ventilation was associated with a parallel reduction of DAD in patients with moderate or severe ARDS, suggesting that low tidal volumes may attenuate DAD.

\section{Radiographic severity and clinical implications}

It has been shown that patients with ARDS with diffuse opacities may differ from those with lobar opacities [21-24]. In a previous study, patients with diffuse ARDS were found to be more likely to have pulmonary ARDS, and also had lower respiratory compliance and higher mortality, than those with lobar ARDS [21]. The same authors found that lung morphology markedly influenced the effects of PEEP [22]. Indeed, PEEP induced marked alveolar recruitment in patients with diffuse opacities, whereas in patients with lobar opacities, PEEP induced mild alveolar recruitment associated with overdistention of previously aerated lung areas [22]. The authors suggested that in cases of lobar ARDS, there was mechanical loss of aeration in the lower lobes, whereas in cases of diffuse ARDS, an inflammatory mechanism may have occasioned aeration loss. In another study, effects of the prone position were more pronounced, with better oxygenation improvement in patients with lobar ARDS than in those with diffuse ARDS [23]. In a recent study, plasma biomarkers such as the soluble form of the receptor for advanced glycation end products or plasminogen activator inhibitor-1 were higher in diffuse ARDS than in lobar ARDS [24]. The high levels of these markers resulted from DAD and were associated with higher mortality. Consequently, patients with diffuse ARDS with extensive opacities involving the four quadrants could represent a homogeneous subphenotype of ARDS with behavior different from the others. Recently, Calfee and colleagues described several subphenotypes of ARDS that may have different responses to therapeutic strategies $[25,26]$. In a subanalysis of a randomized controlled trial, the authors found that high PEEP levels decreased mortality only in a subgroup of patients characterized by particularly severe inflammation [26]. These patients were more likely than others to experience shock, metabolic acidosis, and higher levels of inflammatory biomarkers, and their outcomes were noticeably worse. ARDS is a syndrome involving highly heterogeneous patients, and identification of homogeneous subphenotypes could have an impact on the effects of different therapeutic strategies.

\section{Limitations}

Obviously, clinical autopsy allows for analysis only of patients who have died, and therefore previously they have been among the most severely ill. Nearly half of the patients had severe ARDS at the time of death, and histological findings may differ from those in patients with less severe ARDS. However, in only $20 \%$ of cases was refractory hypoxemia the main reason for death. Although a high proportion of patients indeed died with ARDS, the proximate cause of death was septic shock, cardiac arrest, or withdrawal of life support. Because the latter was not always directly related to ARDS, these patients did not present the most pronounced respiratory severity at the time of death. In fact, they were in different stages of respiratory severity at the time of death, including $14 \%$ of those with mild ARDS, which means that our result could remain generalizable to patients with less severe ARDS. By contrast, open lung biopsy series included a subgroup of patients who may not have been representative; in fact, they were limited to those with persistent ARDS beyond 5-7 days without an identified cause [8-14], which represented only a small proportion of patients with ARDS.

Our study was conducted in a single center and over a lengthy period of time, at a time when ventilator strategies were markedly evolving, especially after 2000 and the widespread use of low tidal volumes [27-29]. A major limitation is that we could not collect accurate tidal volumes in milligrams per kilogram of predicted body weight over the whole period of the study, and consequently, although reduction in tidal volumes was associated with a parallel reduction in the incidence of $\mathrm{DAD}$, we cannot assert that high tidal volumes really promote DAD. Similarly, we could not collect records of plateau pressure in all patients, and we calculated dynamic instead of static compliance and static driving pressure.

Another limitation was due to interobserver variability in the analysis of chest radiographs [30,31], which may have led to misinterpretation of bilateral opacities. Normal lungs were found in $8 \%$ of the patients at autopsy examination, meaning that bilateral opacities seen on chest radiographs were probably atelectasis recruited during inflation at high pressure before microscopic analysis. In a previous study in which researchers 
compared the accuracy of chest radiography with computed tomography for the diagnosis of ARDS, many patients with ARDS based on computed tomography were detected using chest radiography [32]. However, sensitivity was higher for diffuse ARDS than for focal ARDS, and consequently diffuse opacities involving the four quadrants seem likely easier to identify.

DAD proportion may depend on the definition of ARDS that is being applied. In our study, the proportion of DAD was only $45 \%$ among all patients fulfilling the criteria for ARDS according to the Berlin definition (i.e., using "bilateral opacities" as radiologic criteria involving two, three, or four quadrants). In a previous study, the proportion of DAD reached $66 \%$ among all patients fulfilling the criteria for ARDS according to the American-European Consensus Conference definition and using diffuse opacities involving the four quadrants as radiologic criteria [4]. These two findings confirm the higher proportion of DAD among the most hypoxemic patients and those with diffuse infiltrates.

\section{Conclusions}

In this large-scale study of clinical autopsies, a typical histological pattern of DAD was observed in only $45 \%$ of patients with ARDS. The four markers independently associated with the presence of DAD were duration of ARDS $>3$ days, severe hypoxemia, more increased dynamic driving pressure, and extensive opacities involving the four quadrants. Radiographic severity was a strong marker of DAD easily assessed at the bedside. Whether these patients may require specific therapeutic strategies is a matter requiring further investigation.

\section{Abbreviations}

ARDS: Acute respiratory distress syndrome; $C_{\text {RS}}$ : Respiratory system compliance; DAD: Diffuse alveolar damage; $\mathrm{FiO}_{2}$ : Fraction of inspired oxygen; ICU: Intensive care unit; MV: Mechanical ventilation; $\mathrm{PaCO}_{2}$ : Partial pressure of arterial carbon dioxide; $\mathrm{PaO}_{2}$ : Partial pressure of arterial oxygen; $\mathrm{PaO}_{2} /$ $\mathrm{FiO}_{2}$ : Ratio of partial pressure of arterial oxygen to fraction of inspired oxygen; PEEP: Positive end-expiratory pressure; SAPS II: Simplified Acute Physiology Score II; VE: Minute ventilation; VECORR: Corrected expired volume per minute

\section{Acknowledgements}

We thank Jeffrey Arsham, American translator, for reviewing and editing the manuscript.

\section{Funding}

None.

\section{Authors' contributions}

AWT drafted the work and made substantial contributions to the analysis and interpretation of data. PFS, JMR, JAA, and JP acquired data, critically revised the work for important intellectual content, and gave final approval of the version to be published. AWT, OP, JAL, AE, and FFV designed the work, interpreted data for the work, critically revised the work for important intellectual content, and gave final approval of the version to be published. All authors read and approved the final manuscript.

\section{Ethics approval and consent to participate}

We systematically requested informed consent from patients' relatives for both clinical autopsies and potential use of tissue samples for subsequent data analysis in research or teaching purposes. The study was approved by the institutional review board of the University Hospital of Getafe.

\section{Consent for publication}

We obtained all necessary consent from patients' next of kin for the study.

\section{Competing interests}

The authors declare that they have no competing interests.

\section{Publisher's Note}

Springer Nature remains neutral with regard to jurisdictional claims in published maps and institutional affiliations.

\section{Author details}

${ }^{1} \mathrm{CHU}$ de Poitiers, Réanimation Médicale, Poitiers, France. ${ }^{2}$ INSERM CIC 1402 ALIVE Group, Université de Poitiers, 2 rue la Milétrie, 86021 Poitiers Cedex, France. ${ }^{3}$ Departamento de Cuidados Intensivos, Hospital Universitario de Getafe, Madrid, Spain. ${ }^{4}$ CIBER de Enfermedades Respiratorias, Universidad Europea de Madrid, Madrid, Spain. ${ }^{5}$ Departamento de Anatomía Patológica, Hospital Universitario de Getafe, CIBER de Enfermedades Respiratorias, Madrid, Spain. ${ }^{6}$ Departamento de Radiodiagnóstico, Hospital Universitario de Getafe, Madrid, Spain.

Received: 12 July 2017 Accepted: 28 September 2017

Published online: 20 October 2017

\section{References}

1. Ashbaugh DG, Bigelow DB, Petty TL, Levine BE. Acute respiratory distress in adults. Lancet. 1967;2(7511):319-23.

2. Katzenstein AL, Bloor CM, Leibow AA. Diffuse alveolar damage-the role of oxygen, shock, and related factors: a review. Am J Pathol. 1976;85(1):209-28.

3. Tomashefski Jr JF. Pulmonary pathology of acute respiratory distress syndrome. Clin Chest Med. 2000;21(3):435-66.

4. Esteban A, Fernandez-Segoviano P, Frutos-Vivar F, Aramburu JA, Najera L, Ferguson ND, Alia I, Gordo F, Rios F. Comparison of clinical criteria for the acute respiratory distress syndrome with autopsy findings. Ann Intern Med. 2004;141(6):440-5.

5. de Hemptinne Q, Remmelink M, Brimioulle $S$, Salmon I, Vincent JL. ARDS: a clinicopathological confrontation. Chest. 2009;135(4):944-9.

6. Sarmiento X, Guardiola JJ, Almirall J, Mesalles E, Mate JL, Soler M, Klamburg J. Discrepancy between clinical criteria for diagnosing acute respiratory distress syndrome secondary to community acquired pneumonia with autopsy findings of diffuse alveolar damage. Respir Med. 2011;105(8):1170-5.

7. Thille AW, Esteban A, Fernandez-Segoviano P, Rodriguez JM, Aramburu JA, Penuelas O, Cortes-Puch I, Cardinal-Fernandez P, Lorente JA, Frutos-Vivar F. Comparison of the Berlin definition for acute respiratory distress syndrome with autopsy. Am J Respir Crit Care Med. 2013;187(7):761-7.

8. Patel SR, Karmpaliotis D, Ayas NT, Mark EJ, Wain J, Thompson BT, Malhotra A. The role of open-lung biopsy in ARDS. Chest. 2004;125(1):197-202.

9. Papazian L, Doddoli C, Chetaille B, Gernez Y, Thirion X, Roch A, Donati Y, Bonnety M, Zandotti C, Thomas P. A contributive result of open-lung biopsy improves survival in acute respiratory distress syndrome patients. Crit Care Med. 2007;35(3):755-62.

10. Baumann HJ, Kluge S, Balke L, Yekebas E, Izbicki JR, Amthor M, Kreymann G, Meyer A. Yield and safety of bedside open lung biopsy in mechanically ventilated patients with acute lung injury or acute respiratory distress syndrome. Surgery. 2008;143(3):426-33.

11. Charbonney E, Robert J, Pache JC, Chevrolet JC, Eggimann P. Impact of bedside open lung biopsies on the management of mechanically ventilated immunocompromised patients with acute respiratory distress syndrome of unknown etiology. J Crit Care. 2009;24(1):122-8.

12. Willetts L, Parker K, Wesselius $\amalg$, Protheroe CA, Jaben E, Graziano P, Moqbel R, Leslie KO, Lee NA, Lee JJ. Immunodetection of occult eosinophils in lung tissue biopsies may help predict survival in acute lung injury. Respir Res. 2011;12:116.

13. Guerin C, Bayle F, Leray V Debord S, Stoian A, Yonis $H$, Roudaut JB, Bourdin G, Devouassoux-Shisheboran M, Bucher $E$, et al. Open lung 
biopsy in nonresolving ARDS frequently identifies diffuse alveolar damage regardless of the severity stage and may have implications for patient management. Intensive Care Med. 2015;41(2):222-30.

14. Kao KC, Hu HC, Chang CH, Hung CY, Chiu LC, Li SH, Lin SW, Chuang LP, Wang CW, Li LF, et al. Diffuse alveolar damage associated mortality in selected acute respiratory distress syndrome patients with open lung biopsy. Crit Care. 2015;19:228.

15. Cardinal-Fernandez P, Bajwa EK, Dominguez-Calvo A, Menendez JM, Papazian L, Thompson BT. The presence of diffuse alveolar damage on open lung biopsy is associated with mortality in patients with acute respiratory distress syndrome: a systematic review and meta-analysis. Chest. 2016;149(5):1155-64

16. Definition Task Force ARDS. Acute respiratory distress syndrome: the Berlin definition. JAMA. 2012;307(23):2526-33.

17. Thille AW, Esteban A, Fernandez-Segoviano P, Rodriguez JM, Aramburu JA Vargas-Errazuriz P, Martin-Pellicer A, Lorente JA, Frutos-Vivar F. Chronology of histological lesions in acute respiratory distress syndrome with diffuse alveolar damage: a prospective cohort study of clinical autopsies. Lancet Respir Med. 2013:1(5):395-401.

18. Tejerina E, Esteban A, Fernandez-Segoviano P, Frutos-Vivar F, Aramburu J, Ballesteros D, Rodriguez-Barbero JM. Accuracy of clinical definitions of ventilator-associated pneumonia: comparison with autopsy findings. J Crit Care. 2010;25(1):62-8.

19. Tejerina E, Esteban A, Fernandez-Segoviano P, Maria Rodriguez-Barbero J, Gordo F, Frutos-Vivar F, Aramburu J, Algaba A, Gonzalo Salcedo Garcia O, Lorente JA. Clinical diagnoses and autopsy findings: discrepancies in critically ill patients. Crit Care Med. 2012;40(3):842-6.

20. Lorente JA, Cardinal-Fernandez P, Munoz D, Frutos-Vivar F, Thille AW, Jaramillo C, Ballen-Barragan A, Rodriguez JM, Penuelas O, Ortiz G, et al. Acute respiratory distress syndrome in patients with and without diffuse alveolar damage: an autopsy study. Intensive Care Med. 2015; 41(11):1921-30

21. Rouby JJ, Puybasset L, Cluzel P, Richecoeur J, Lu Q, Grenier P, CT Scan ARDS Study Group. Regional distribution of gas and tissue in acute respiratory distress syndrome. II. Physiological correlations and definition of an ARDS severity score. Intensive Care Med. 2000:26(8):1046-56.

22. Puybasset L, Gusman P, Muller JC, Cluzel P, Coriat P, Rouby JJ, CT Scan ARDS Study Group. Regional distribution of gas and tissue in acute respiratory distress syndrome. III. Consequences for the effects of positive end-expiratory pressure. Intensive Care Med. 2000;26(9):1215-27.

23. Galiatsou E, Kostanti E, Svarna E, Kitsakos A, Koulouras V, Efremidis SC, Nakos G. Prone position augments recruitment and prevents alveolar overinflation in acute lung injury. Am J Respir Crit Care Med. 2006; 174(2):187-97.

24. Mrozek S, Jabaudon M, Jaber S, Paugam-Burtz C, Lefrant JY, Rouby J, Asehnoune K, Allaouchiche B, Baldesi O, Leone M, et al. Elevated plasma levels of sRAGE are associated with nonfocal CT-based lung imaging in patients with ARDS: a prospective multicenter study. Chest. 2016;150(5):998-1007.

25. Calfee CS, Delucchi K, Parsons PE, Thompson BT, Ware LB, Matthay MA. Subphenotypes in acute respiratory distress syndrome: latent class analysis of data from two randomised controlled trials. Lancet Respir Med. 2014;2(8):611-20.

26. Famous KR, Delucchi K, Ware LB, Kangelaris KN, Liu KD, Thompson BT, Calfee CS, ARDS Network. Acute respiratory distress syndrome subphenotypes respond differently to randomized fluid management strategy. Am J Respir Crit Care Med. 2017;195(3):331-8.

27. Acute Respiratory Distress Syndrome Network. Ventilation with lower tidal volumes as compared with traditional tidal volumes for acute lung injury and the acute respiratory distress syndrome. N Engl J Med. 2000;342(18):1301-8.

28. Esteban A, Ferguson ND, Meade MO, Frutos-Vivar F, Apezteguia C, Brochard L, Raymondos K, Nin N, Hurtado J, Tomicic V, et al. Evolution of mechanical ventilation in response to clinical research. Am J Respir Crit Care Med. 2008;177(2):170-7.

29. Esteban A, Frutos-Vivar F, Muriel A, Ferguson ND, Penuelas O, Abraira V, Raymondos K, Rios F, Nin N, Apezteguia C, et al. Evolution of mortality over time in patients receiving mechanical ventilation. Am J Respir Crit Care Med. 2013;188(2):220-30.

30. Rubenfeld GD, Caldwell E, Granton J, Hudson LD, Matthay MA. Interobserver variability in applying a radiographic definition for ARDS. Chest. 1999;116(5):1347-53.
31. Meade MO, Cook RJ, Guyatt GH, Groll R, Kachura JR, Bedard M, Cook DJ, Slutsky AS, Stewart TE. Interobserver variation in interpreting chest radiographs for the diagnosis of acute respiratory distress syndrome. Am J Respir Crit Care Med. 2000;161(1):85-90.

32. Figueroa-Casas JB, Brunner N, Dwivedi AK, Ayyappan AP. Accuracy of the chest radiograph to identify bilateral pulmonary infiltrates consistent with the diagnosis of acute respiratory distress syndrome using computed tomography as reference standard. J Crit Care. 2013;28(4):352-7.

\section{Submit your next manuscript to BioMed Central and we will help you at every step:}

- We accept pre-submission inquiries

- Our selector tool helps you to find the most relevant journal

- We provide round the clock customer support

- Convenient online submission

- Thorough peer review

- Inclusion in PubMed and all major indexing services

- Maximum visibility for your research

Submit your manuscript at www.biomedcentral.com/submit 